\title{
The production of Benzaldehyde by Rhizopus oligosporus USM R1 in a Solid State Fermentation (SSF) System of Soy Bean Meal: rice husks
}

\author{
Norliza, A. W. ${ }^{1}$ and Ibrahim, C.O. ${ }^{2^{*}}$ \\ ${ }^{2}$ Fermentation and Enzyme Technology Laboratory, School of Biological Sciences, \\ Universiti Sains Malaysia, 11800 Minden, Penang, Malaysia. \\ ${ }^{1}$ Cocoa Downstream Research Centre, Malaysian Cocoa Board, Lot 3, Jln P/9B, Section 13, \\ 43650 Bandar Baru Bangi, Selangor, Malaysia. \\ Email: oibrahim@usm.my
}

\begin{abstract}
The cultivation of Rhizopus oligosporus USM R1 for the production of benzaldehyde, a bitter cherry almond flavour was performed using soya bean meal and rice husks as the substrates. The identification of $R$. oligosporus USM R1 was performed based on the observation made under light microscope and scanning electron microscope (SEM). The optimum conditions for the SSF in a $250-\mathrm{ml}$ Erlenmeyer flask system were $40 \%(\mathrm{v} / \mathrm{w})$ water content, substrate particle size of $0.7 \mathrm{~mm}$; inoculum size of $1 \times 10^{5}$ spores $/ \mathrm{g}$ substrate; incubation temperature of $30^{\circ} \mathrm{C}$; substrate amount of $7 \mathrm{~g}$ and the ratio of soy bean meal: rice husks of 50:50\%. A maximum benzaldehyde production was obtained when the substrate was agitated after 48 hour for a 96 hour fermentation time. The highest benzaldehyde production obtained after 96 hour cultivation was $5.47 \mathrm{mg} \mathrm{g}^{-1}$ substrate. The supplementation of carbon and nitrogen sources in the substrate mixture revealed an enhancement in the growth and benzyldehyde production. A maximum production of benzaldehyde was obtained with the supplementation of L-phenylalanine, a precursor for benzaldehyde biosynthesis which gave 38.69 $\mathrm{mg}$ benzaldehyde/g substrate. This is approximately 6 -folds higher compared to the substrates without the supplementation of L-phenylalanine.
\end{abstract}

Keywords: Rhizopus oligosporus, solid state fermentation system (SSF), benzaldehyde, L-phenylalanine

\section{INTRODUCTION}

Due to the consumer's preference towards aromas from biological origin rather than synthetic aromas, the synthesis of natural compounds as flavour by biotechnological processes plays an increasing role in the flavour industry. Some of the flavouring compounds include the aromatic aldehydes vanillin, cinnamaldehyde and benzaldehyde (bitter almond aroma) which were found to have commercial value for industrial consumption. Benzaldehyde is the second most important flavouring compound after vanillin (Welsh et al., 1989). Natural benzaldehyde can be found as a glycoside (amygdalin) in the pits of almonds and cherries and was extracted using chemical methods. However, the main drawback of the method is the formation of toxic byproducts, such as hydrocyanic acid. Benzaldehyde can also be synthesized chemically via toluene chlorination, however, the process was found to be environmental unfriendly as it requires heavy metals as catalysts with high energy cost and the by-products contain undesirable racemic mixtures (Lawrence and Yuan, 1996).

Therefore, the production of natural benzaldehyde through fermentation processes was considered. Microbial production of benzaldehyde from phenylalanine have been reported in a submerged fermentation system using several microorganisms such as Lactobacillus plantarum (Nierop Groot and De Bont, 1998), Polyporus tuberaster

${ }^{*}$ Corresponding author
(Kawabe and Morita, 1994) and Phanerochaete chrysosporium (Jensen et al., 1994). Among bacteria, benzaldehyde formation has was from Pseudomonas putida via the mandelic acid pathway (Tsou et al., 1990). Incubation of a cell extract of Lactobacillus plantarum with phenylalanine revealed that benzaldehyde was indeed formed (Nierop Groot and De Bont, 1998). Benzaldehyde production from phenylalanine in a SSF process has not been reported. However, benzaldehyde production using a direct SSF process has not been reported using a locally isolated, Penicillium diversum cultivated in a palm kernel cake as substrate (Leong and Ibrahim, 2000). SSF can be defined as a method of culturing microorganisms on and/ or within the particles of a solid matrix. It is generally a simple process and requires less energy than submerged fermentation system. Furthermore, the low operational cost of SSF, high productivity, low waste water output and improved product recovery has made SSF processes attractive for large scale production system of microbial metabolites (Bhattacharyya et al., 1998).

In this study, Rhizopus oligosporus, USM R1, a potential indigenous filamentous fungus was selected for the production of benzaldehyde via the SSF system using soy bean meal and rice husks as substrates. This paper describes the optimization of the cultural conditions on the production of benzaldehyde by the fungus. 


\section{MATERIALS AND METHODS}

Selection and identification of the potential fungal isolates for benzaldehyde production

The fungal isolates for the selection of potential benzaldehyde producers were obtained either from soil samples, local fermented foods and from the culture collection from Fermentation and Enzyme Technology Laboratory (FETL), Universiti Sains Malaysia, Penang, Malaysia. The selection was based on a screening programme in the SSF system using $10 \mathrm{~g}$ of substrate containing either ground nut meal, soy bean meal, palm kernel cake, green pea meal, or baked bean meal mixed with rice husk as the substrate mixture at the ratio of $1: 1$ in a $250-\mathrm{ml}$ Erlenmeyer flask inoculated with $4 \mathrm{ml}$ of spore suspension of concentration $1 \times 10^{5}$ spores $/ \mathrm{ml}$. Cultivation was performed for 4 days at $30^{\circ} \mathrm{C}$. Identification of the potential producer was carried based on the morphological and structural characteristics of the fungus observed under the light and scanning electron microscope (Leica Cambridge S360). The identification was confirmed based on the fungal characteristics described by Fassatiova (1986).

\section{Cultivation system of SSF for benzaldehyde production}

Soy bean meal and rice husks were sieved to the particle sizes of $0.7 \mathrm{~mm}$ and $1.0 \mathrm{~mm}$, respectively. The ability of the potential isolate to produce benzaldehyde on soy bean meal: rice husks in a SSF system was determined using the fermentation medium consisting of $5 \mathrm{~g}$ soy bean meal and $5 \mathrm{~g}$ of rice husks in a $250 \mathrm{ml}$ Erlenmeyer flask. The medium was autoclaved at $121^{\circ} \mathrm{C}$ for $15 \mathrm{~min}$. The substrate was inoculated with $4 \mathrm{ml}$ of spore suspension of concentration $1 \times 10^{5}$ spores $/ \mathrm{ml}$. Incubation was carried out at $30^{\circ} \mathrm{C}$ and after 4 days of cultivation, benzaldehyde production and fungal growth were analysed. This fermentation conditions were used as the basal conditions in the optimization experiments.

\section{Extraction and determination of benzaldehyde concentration}

Benzaldehyde that was secreted extracellularly was extracted by adding $10 \mathrm{~g}$ of the fermented substrate in 25 $\mathrm{ml}$ of $0.2 \mathrm{M}$ acetate buffer containing $0.1 \%$ Tween 80 . The mixture was vigorously homogenized for $10 \mathrm{~min}$, followed by filtration through Muslin cloth. The filtrate collected was centrifuged for $20 \mathrm{~min}$ at $5,000 \mathrm{rpm}$. The supernatant collected after centrifugation was diluted accordingly using distilled water and was used as the source of benzaldehyde. The concentration of benzaldehyde expressed as mg benzaldehyde produced $\mathrm{g}^{-1}$ substrate was determined spectrophotometrically at $245 \mathrm{~nm}$ (Lawrence and Yuan, 1996) against a standard curve obtained from the commercially available benzaldehyde (Sigma).

\section{Determination of fungal growth}

The growth of the fungus was determined by the modified method described by Swift (1972) based on spectrophotometric measurement of glucosamine at 530 $\mathrm{nm}$. The amount of glucosamine released from the fungus which was expressed as $\mathrm{mg} \mathrm{g}^{-1}$ substrate was determined based on the standard curve of glucosamine (Sigma).

Optimization of the cultural conditions on benzaldehyde production by isolate USM R1

Based on the basal cultural conditions, the SSF parameters optimized include cultivation temperatures (25 $\left.-45^{\circ} \mathrm{C}\right)$, amount of substrates $(7-30 \mathrm{~g})$, inoculum sizes $\left(1 \times 10^{3}-1 \times 10^{6}\right)$, water content $(30-70 \%, v / w)$ and the frequencies of substrate agitation. Cultivation was carried out using the soy bean meal - rice husks mixture as substrates in a 250-ml Erlenmeyer flask for 4 days. All the cultivations were performed in triplicates.

\section{Effect of supplementation of carbon and nitrogen sources on benzaldehyde production.}

The effect of supplementation of carbon and nitrogen sources was studied using the cultivation conditions consisting of soy bean meal of particle size $0.7 \mathrm{~mm}$ with $1.0 \mathrm{~mm}$ rice husk at the ratio of $1: 1$, cultivation temperature $30^{\circ} \mathrm{C}$, substrate amount of $7 \mathrm{~g}$, inoculum size $1 \times 10^{5}$ spores $/ \mathrm{ml}$ and $40 \%(\mathrm{v} / \mathrm{w})$ of water content. Cultivation was carried out for 4 days with agitation after every $48 \mathrm{hr}$. The carbon and nitrogen sources were added to the substrate at the concentration of $10 \%(\mathrm{w} / \mathrm{w})$. The carbon sources examined include fructose, glucose arabinose, lactose, sucrose, maltose, raffinose, soluble starch, cellulose and dextrin, while the nitrogen sources include the organic and inorganic nitrogen sources and amino acids.

\section{RESULTS}

\section{Selection and identification of isolate USM R1}

The selection of potential benzyldehyde producing fungus was carried out using the SSF culture system. From a total of 24 fungal isolates tested, isolate USM R1 was selected as a potential producer based on the highest production of benzaldehyde with a production of $2.87 \mathrm{mg}$ benzyldehyde $\mathrm{g}^{-1}$ substrate and growth of $2.35 \mathrm{mg}$ glucosamine $\mathrm{g}^{-1}$ substrate using soy bean meal and rice husk as the substrates. The morphological and structural characteristics of isolate USM R1 were examined under the Scanning Electron Microscope and Light Microscope. It was observed that the sporangium developed at the end of the sporangiophore was globose in shape (Figure 1). The sporangiospores also possessed similar globose shape (Figure 1). Branching of mycelia at the base of sporangiophore into structure known as rhizoid and stolon can be used to differentiate between Rhizopus sp. and Mucor sp. (Figure 2). Based on the taxonomic studies 
described by Pitt and Hocking (1999), five species of Rhizopus were identified comprising of Rhizopus sexualis, $R$. stolonifer, $R$. oryzae, $R$. oligosporus and $R$. microporus. Isolate USM R1 with the diameter of columella of about 75 $\mu \mathrm{m}$ with spinose wall sporangiospores of about $4 \mu \mathrm{m}$ falls in the species of $R$. oligosporus. Larger collumela diameter were observed in Rhizopus sexualis, $R$. stolonifer, and $R$. oryzae, while $R$. microsporus possessed smaller columella diameter of about $40 \mu \mathrm{m}$. Furthermore, no septum can be seen on the sporangiophore. It was also observed that both the columella and aphophysis were either globose or subglobose. Matured sporangium will release a bunch of sporangiospores and immediately transformed into a structure that looks like 'umbrella'. Based on these morphological and structural characteristics, isolate USM R1 was identified as Rhizopus oligosporus USM R1. Other benzaldehyde producing fungi that have been reported include Bjerkandera adusta, Ishcnoderma benzoinum, Dichomitus squalens (Lapadatescu et al., 1997) and Trichosporon beigelii (Casey and Dobb, 1992).

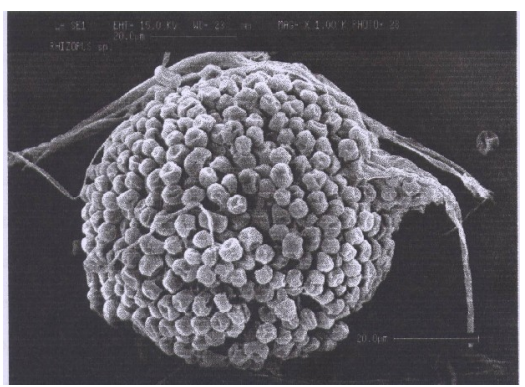

Figure 1: Electron micrograph of the sporangium and sporangiospores of Rhizopus oligosporus USM R1

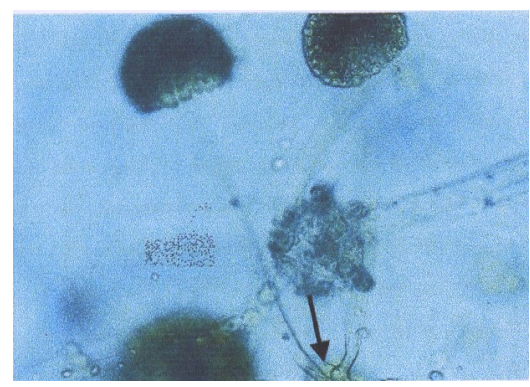

Figure 2: Branching of mycelia of Rhizopus oligosporus USM R1 at the base of sporangiophore to form rhizoid seen under light microscope.

(Arrow indicates the branching of mycelia, magnification 200X)
The effect of cultural conditions on the benzaldehyde production by $R$. oligosporus USM R1

The effect of incubation temperature on the production of benzaldehyde and growth of R.oligosporus is shown in Figure 3. It was observed that the temperatures in the range of $30-40^{\circ} \mathrm{C}$ have resulted in the highest benzaldehyde production of about $3.17-3.24 \mathrm{mg} \mathrm{g}^{-1}$ substrate after $96 \mathrm{hr}$ of cultivation indicating there were no significant differences between those temperatures. It was also observed that the fungal growth corresponded to benzaldehyde production. However, the temperature of $30^{\circ} \mathrm{C}$ was chosen in the subsequent experiments due to lower production cost as compared to higher temperatures. Higher temperatures of more than $40^{\circ} \mathrm{C}$ were found unfavourable for benzaldehyde production by R. oligosporus USM R1.

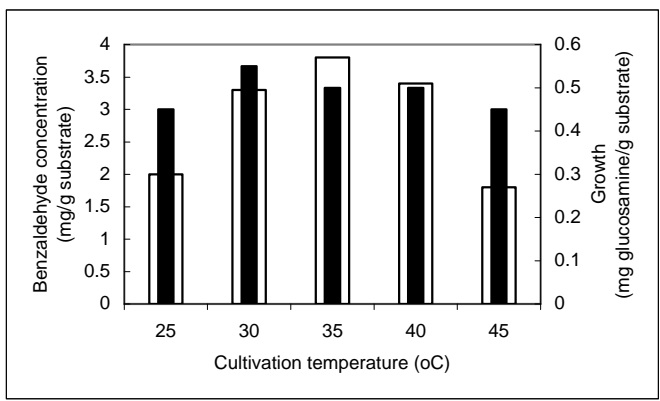

Figure 3: Effect of fermentation temperature on the growth and benzaldehyde production by $R$. oligosporus USM R1 in SSF system.

Cultivation conditions: as described in Materials and Methods.

Symbols: ( $\square$ ) benzaldehyde concentration and (ם) growth.

Figure 4 shows the effect of the amount of substrate on benzaldehyde production. Seven grams of substrate resulted in a maximum benzaldehyde production of 3.17 $\mathrm{mg} \mathrm{g}^{-1}$ substrate, while other substrate amount of 10,15 , 20 and $30 \mathrm{~g}$ resulted in lower benzaldehyde production ranging from $2.75-3.0 \mathrm{mg} \mathrm{g}^{-1}$ substrate with the growth in the range of $0.4-0.5 \mathrm{mg}$ glucosamine $\mathrm{g}^{-1}$ substrate. $A$ significant correlation between benzaldehyde production and fungal growth was observed.

The effect of inoculum sizes on benzaldehyde production is shown in Figure 5 . It was found that the maximum benzaldehyde production from $R$. oligosporus was obtained with the inoculum size of $1 \times 10^{5}$ spores $/ \mathrm{ml}$ which gave $3.33 \mathrm{mg}$ benzaldehyde $\mathrm{g}^{-1}$ substrate with the growth of about $0.5 \mathrm{mg}$ glucosamine $\mathrm{g}^{-1}$ substrate. Again, benzaldehyde production was observed to be growth dependent. 


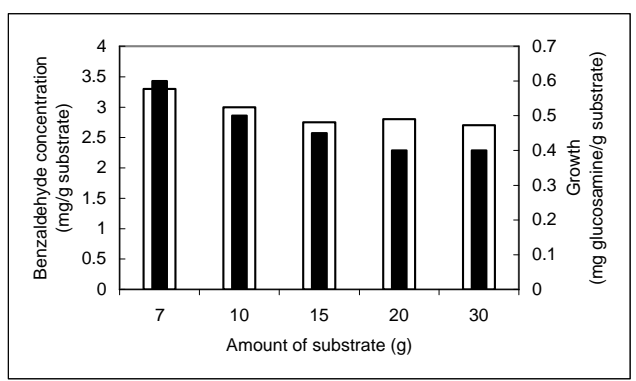

Figure 4: Effect of substrate amount on the growth and benzaldehyde production by $R$. oligosporus USM R1 in SSF system.

Cultivation conditions: as described in Materials and Methods.

Symbols: ( $\square$ ) benzaldehyde concentration and ( $\square$ ) growth.

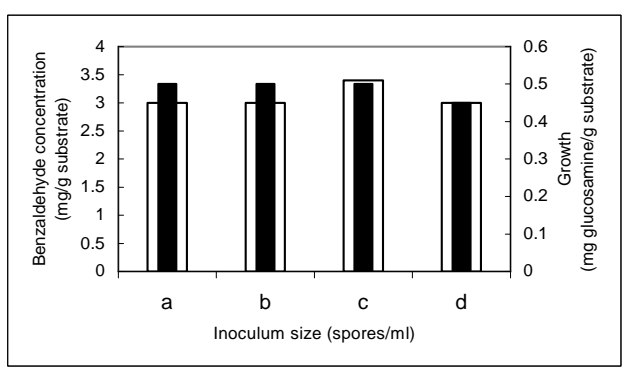

Figure 5: Effect of inoculum size on the growth and benzaldehyde production by $R$. oligosporus USM R1 in SSF system.

Cultivation conditions: as described in Materials and Methods. a: $1 \times 10^{3}$; b: $1 \times 10^{4}$; c: $1 \times 10^{5}$; d: $1 \times 10^{6}$ spores $\mathrm{g}^{-1}$ substrates.

Symbols: $(\square)$ benzaldehyde concentration and ( $\square$ ) growth.

The effect of water content in the substrate was determined from $30-70 \%(\mathrm{v} / \mathrm{w})$. As shown in Figure 6, it was observed that the optimum water content was $40 \%$ $(\mathrm{v} / \mathrm{w})$ with benzaldehyde production of $4.20 \mathrm{mg} \mathrm{g}^{-1}$ substrate and fungal growth of about $0.45 \mathrm{mg}$ glucosamine $\mathrm{g}^{-1}$ substrate. Water content of higher than $40 \%(\mathrm{v} / \mathrm{w})$ did not improve the productivity of the benzaldehyde.

The concentration of oxygen in the SSF system is important in ensuring good fungal growth. Enhanced aeration in the substrate can be achieved by substrate agitation. Agitation enables mixing of the substrates and allows distribution of water content and oxygen (Silman et al., 1979).The effect of the rate of agitation was determined on the growth and benzaldehyde production by $R$. oligosporus USM R1 in the SSF system. As shown in Figure 7, it was observed that the substrate agitation after 48 hour of cultivation resulted in the maximum benzaldehyde production of $5.14 \mathrm{mg}$ benzaldehyde $\mathrm{g}^{-1}$ substrate and the growth of about $0.7 \mathrm{mg}$ glucosamine $\mathrm{g}^{-1}$ substrate. On the other hand, it was also observed that continuous agitation of substrate resulted in low benzaldehyde production of only $1.3 \mathrm{mg} \mathrm{g}^{-1}$ substrate which was essentially due to the disruption of the mycelia into inactive fragments. This is evident from the nonagitated cultivation experiments which resulted in higher growth.

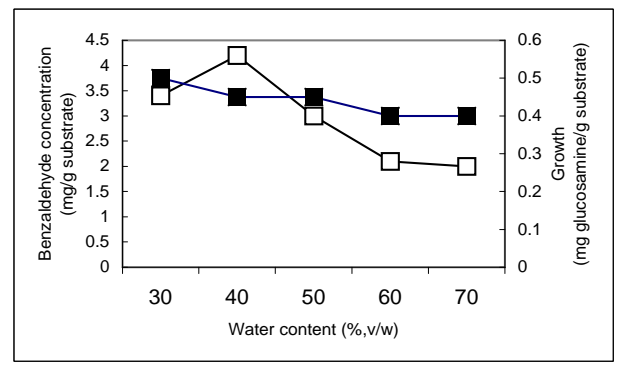

Figure 6: Effect of water content on the growth and benzaldehyde production by $R$. oligosporus USM R1 in SSF system.

Cultivation conditions: as described in Materials and Methods

Symbols: ( $\square$ ) benzaldehyde concentration and (ם) growth.

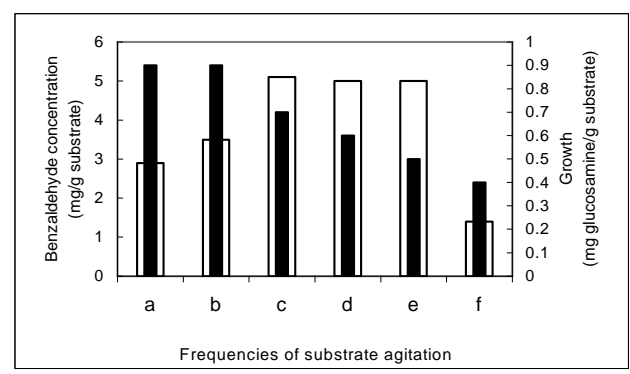

Figure 7: Effect of frequencies of substrate agitation on the growth and benzaldehyde production by $R$. oligosporus USM R1 in SSF system.

Cultivation conditions: as described in Materials and Methods. a: Control (without agitation); b: agitation after 24 hour; c: agitation after 48 hour; d: agitation every 24 hour; e: agitation every 12 hour; f: continuous agitation at $28 \mathrm{rpm}$.

Symbols: $(\square)$ benzaldehyde concentration and (ם) growth.

\section{The effect of supplementation of nitrogen sources in} the SSF substrates

Nutritional values of substrates used in the SSF are the main limiting factors for the growth of fungi and subsequently the production of its metabolites (Righelato, 1975). Therefore, the effect of supplementation of carbon and nitrogen sources in the SSF substrates was examined. Table 1 and Table 2 show the effect of the 
supplementation of various carbon sources and various nitrogen sources, respectively. As shown in Table 1, it was found that the supplementation of carbon sources enhanced the growth of the fungus which subsequently enhanced benzaldehyde production. All the carbon sources examined showed higher growth and benzaldehyde production compared to the cultivation without the supplementation of any carbon sources, with glucose showing the highest growth of $1.36 \mathrm{mg}$ glucosamine $\mathrm{g}^{-1}$ substrate and benzyldehyde production of $14.84 \mathrm{mg}$ benzaldehye $\mathrm{g}^{-1}$ substrate. On the other hand, the addition of various nitrogen sources enhanced the benzaldehyde production significantly (Table 2). The addition of amino acids increased the benzaldehyde production in the range of $9-39 \mathrm{mg}^{\text {benzaldehyde } \mathrm{g}^{-1}}$ substrate compared to only about $5 \mathrm{mg}$ benzaldehyde $\mathrm{g}^{-1}$ substrate in the cultivation without any additional nitrogen sources. The growth was in the range of $1.1-1.4 \mathrm{mg}$ glucosamine $\mathrm{g}^{-1}$ substrate which was also higher than the control of $0.65 \mathrm{mg}$ glucosamine $\mathrm{g}^{-1}$ substrate. Although inorganic nitrogen sources resulted in moderate benzaldehyde production ranging from $7-9 \mathrm{mg}$ benzaldehyde $\mathrm{g}^{-1}$ substrate, they were still higher than the control cultivation system without the addition of any nitrogen sources supplementation. Among the amino acids, the supplementation of L-phenylalanine in the substrate mixture resulted in a significantly high benzaldehyde production of $38.69 \mathrm{mg} \mathrm{g}^{-1}$ substrate, which, is approximately 6 folds higher than the cultivation without the supplementation of any nitrogen sources. Complex nitrogen sources also resulted in significant amount of benzaldehyde production with yeast extract resulted in a significant benzaldehyde production of 31.21 $\mathrm{mg} \mathrm{g}^{-1}$ substrate and the growth of $1.49 \mathrm{mg}$ glucosamine $\mathrm{g}^{-1}$ substrate.

Table 1: Effect of supplementation of carbon sources in the soy bean meal -rice husk substrate mixtures.

\begin{tabular}{lll}
\hline Carbon sources & $\begin{array}{l}\text { Glucosamine } \\
\text { ( } \mathbf{g ~ g}^{-1} \text { substrate) }\end{array}$ & $\begin{array}{l}\text { Benzaldehyde } \\
\left(\mathbf{m g ~ g}^{-1} \text { substrate }\right)\end{array}$ \\
\hline Control* & & \\
Fructose & $0.65 \pm 0.02$ & $5.14 \pm 0.01$ \\
D-glucose & $1.36 \pm 0.01$ & $14.65 \pm 0.00$ \\
L-arabinose & $1.36 \pm 0.02$ & $14.84 \pm 0.01$ \\
Lactose & $1.21 \pm 0.01$ & $10.88 \pm 0.02$ \\
Maltose & $1.17 \pm 0.01$ & $8.72 \pm 0.01$ \\
D-sucrose & $1.20 \pm 0.01$ & $9.98 \pm 0.01$ \\
Raffinose & $0.94 \pm 0.01$ & $8.55 \pm 0.01$ \\
Soluble starch & $1.25 \pm 0.01$ & $7.21 \pm 0.01$ \\
Cellulose & $1.15 \pm 0.01$ & $7.70 \pm 0.01$ \\
Dextrin & $1.28 \pm 0.00$ & $7.86 \pm 0.01$ \\
& $1.31 \pm 0.01$ & $7.93 \pm 0.01$
\end{tabular}

( ${ }^{*}$ without any supplementation)

Data were presented as average of triplicates experiments
Table 2: Effect of supplementation of nitrogen sources in the soy bean meal -rice husk substrate mixture

\begin{tabular}{lll}
\hline Nitrogen sources & $\begin{array}{l}\text { Glucosamine } \\
\left.\mathbf{g}^{-1} \text { substrate }\right)\end{array}$ & $\begin{array}{l}\text { Benzaldehyde } \\
\left(\mathbf{m g ~ g}^{-1} \text { substrate }\right)\end{array}$ \\
\hline $\begin{array}{l}\text { Control } \\
\text { L-Lysine }\end{array}$ & $0.65 \pm 0.02$ & $5.14 \pm 0.01$ \\
monohidrochloride & $1.13 \pm 0.01$ & $12.13 \pm 0.01$ \\
DL-aspartic acid & $1.13 \pm 0.01$ & $9.25 \pm 0.01$ \\
L-isoleucine & $1.35 \pm 0.01$ & $9.82 \pm 0.01$ \\
L-glutamine & $1.41 \pm 0.01$ & $9.73 \pm 0.01$ \\
L-methionine & $1.11 \pm 0.01$ & $8.87 \pm 0.01$ \\
L-asparagine & $1.20 \pm 0.02$ & $10.71 \pm 0.01$ \\
L-alanine & $1.17 \pm 0.02$ & $10.82 \pm 0.01$ \\
L-hystidine & $1.31 \pm 0.01$ & $12.26 \pm 0.01$ \\
L-arginine & $1.23 \pm 0.00$ & $14.64 \pm 0.01$ \\
L-proline & $1.08 \pm 0.01$ & $9.47 \pm 0.01$ \\
L-phenylalanine & $1.39 \pm 0.01$ & $38.69 \pm 0.01$ \\
Glycine & $1.07 \pm 0.01$ & $15.93 \pm 0.02$ \\
Yeast extract & $1.49 \pm 0.00$ & $31.21 \pm 0.01$ \\
Casein & $1.13 \pm 0.02$ & $12.83 \pm 0.00$ \\
Peptone & $1.19 \pm 0.01$ & $17.23 \pm 0.01$ \\
Ammonium chloride & $1.06 \pm 0.02$ & $8.57 \pm 0.01$ \\
Ammonium sulphate & $0.95 \pm 0.01$ & $7.06 \pm 0.02$ \\
Ammonium nitrate & $1.18 \pm 0.01$ & $8.97 \pm 0.01$ \\
& & \\
\hline \multirow{*}{*}{ Whithout any supplemen } &
\end{tabular}

( ${ }^{*}$ without any supplementation)

Data were presented as average of triplicates experiments

\section{DISCUSSION}

Many microorganisms are capable of growing on solid substrates, but only filamentous fungi can grow to a significant extent in the absence of free water. A number of these fungi are capable of producing numerous metabolites on the SSF substrates such as enzymes, antimicrobial or flavouring compounds. The flavouring compounds of interest from microbial sources include lactones, methyl ketones, vanillin, benzaldehyde, alcohols, esters, terpenes and others (Feron et al., 1996). Although submerged fermentation processes have been widely used, SSF however, represents an attractive alternative for the manufacture of aroma compounds or flavoured foods for many reasons. Solid substrates or its by-products can be used directly after minimum extraction step and without further pretreatment. In addition, the fermentation conditions are similar to the fungal metabolism in its natural habitat, thus the metabolites synthesized existed in its natural state. In the submerged fermentation, the process control and fermentation design are more complicated than the SSF process which can be operated under low cost. The products obtained in the SSF system are more concentrated than the submerged fermentation processes, which will facilitates product recovery and downstream processing (Balakrishna and Pandey, 1996).

The success of a SSF operation depends strongly on the physical characteristics of the substrates which determine the availability of the nutrients in the substrates to the fungi (Raimbault, 1998). Generally, smaller particle sizes of the substrates provide a larger surface area for 
heat transfer and gas exchanges. Given the same void volume fraction (porosity) and pore size distribution, smaller particle sizes also distribute equivalent moisture concentrations in thinner films on external surfaces exposed to the gas environment. This factor which was suggested by Hesseltine (1972) was one of the major variables in SSF process development. Although fine particle sizes of the substrates allow higher substrate conversion, compactness of the substrates must be avoided. For better porosity of substrate, coarser particles may be added (Laukevics et al., 1984). Therefore, in this study, rice husks having particle size of $1.0 \mathrm{~mm}$ were added into soy bean meal of particle size $0.7 \mathrm{~mm}$ to give a less compact substrate texture.

Fermentation temperature is a very important parameter in SSF (Moo Young et al. 1983). The optimum growth temperature for R.oligosporus USM R 1 was $30^{\circ} \mathrm{C}$, however the production of benzaldehyde was observed to be in the temperature range of $30-40^{\circ} \mathrm{C}$. Similar results were obtained by Roukas (2000) who reported that the production of citric and gluconic acids were optimum in the temperature range of $25-30^{\circ} \mathrm{C}$. The higher end of the temperature was due to the heat generated from the fungal metabolic activities. The reduction of benzaldehyde concentration at $40-45^{\circ} \mathrm{C}$ was mainly due to the unfavourable temperature for fungal growth, inactivation of the biotransformational enzyme systems or due to the dehydration of the substrates (Kargi et al., 1985).

The quantity of substrate in the SSF may also affect several other related factors such as water content and the availability of free oxygen in the substrates needed for optimum growth and benzaldehyde production. High quantity of substrates in small fermentation vessels affect the penetration by the mycelia and thus the assimilation and absorption of the nutrients from the substrates especially by a fungus like, R.oligosporus which is highly aerobic. Under normal circumstances, growth and metabolite production occur on the surface of the substrate, which corresponded to the amount of oxygen availability. Oxygen concentration in the SSF can be manipulated by varying the rate of agitation and aeration. Agitation and aeration conditions are another critical determinants for good growth of the fungi and subsequently the synthesis of its metabolites. An adequate supply of oxygen is important not only in maintaining the aerobic conditions, but also in ventilating excess carbon dioxide evolved during the fermentation. However, many SSF systems are shear sensitive and cannot be agitated vigorously. vigorous agitation caused the disruption of mycelial-substrate contact, particularly for organisms with mycelial-bound enzymes for the hydrolysis of solid polymers in the substrates (Mudgett, 1980). Similar observations was also obtained in the cultivation system of $R$. oligosporus USM R1 which, was continuously agitated throughout the fermentation process, resulting in poor growth and low benzaldehyde production. On the other hand, significant growth and benzyldehyde production was observed when the substrates were agitated after 48 hour of fermentation, which help to improve the aeration within the substrates. Yadav and Tripathi (1991) also reported higher growth of Coriolus versicolor using wheat straw as substrates with interval substrate agitation.

Substrates have an optimum capacity to hold water, and therefore at any given amount of substrate, the amount of water content is fixed, provided no additional water is added or generated from the metabolic activities of the fungi. Moisture or water content is another important factor which regulates the SSF processes. An optimum moisture level in the soy bean meal: rice husks will determine the good growth and benzaldehyde production by the fungus. Ngadi and Correia (1992) reported that low moisture content of the substrate in SSF system reduced the mass transfer processes such as diffusion of solutes and gas to the cell during fermentation. On the other hand, high water content resulted in an increase in substrates compactness and prevented oxygen diffusion, and at the same time, facilitated contamination by fast growing bacteria (Laukevics et al., 1984). The level of water content in the system and its consequences will affect spore germination, growth and benzyldehyde formation.

The rates of spore germination and fungal colonization of the substrates also depend on the density of inoculum used to intiate the fermentation. Low inoculum sizes resulted in lower growth and high possibility of growth of undesirable contaminating microorganisms. On the other hand, high inoculum sizes resulted in rapid germination and higher growth rate which will rapidly deplete the nutrients in the substrates. The depletion of nutrients due to excessive growth will reduce the availability of energy source for product formation (Mudgett, 1980). For R.oligosporus, the optimum inoculum size of $1 \times 10^{5}$ spores $\mathrm{g}^{-1}$ substrate indicated that an equilibrium has been achieved between the growth rate, nutrient availability and rate of consumption and the rate benzyldehyde synthesis in the SSF system.

In most SSF systems, nutrient availability is extremely important in determining good growth. Substrates from agrowaste materials do not provide adequate nutritional requirement for the growth and product synthesis. The fungi must penetrate the substrates and degrade them before assimilation and absorption of the nutrients can take place. Additional supply of the nutrients to the substrates will help to stabilize and enhance the fungal growth, synthesis of intracellular and extracellular proteins and enzymes and subsequently the products formation. Supplementation of the nutrients especially the carbon and nitrogen sources will enhance the fungal growth cycle. In the case of $R$. oligosporus, the supplementation of -phenylalanine in the SSF system, exhibited significant enhancing effect on the benzaldehyde production. Lphenylalanine is an important precursor for benzaldehyde biosynthesis as shown in the mutants of Pseudomonas putida, Polyporus tuberaster and Phanerochaete chrysosporium (Feron et al., 1996). Nierop Groot and De Bont (1998) have shown that enzymatic biotransformation of L-phenylalanine to benzaldehyde canoccur using cell free extracts of several microorganisms. Therefore, it can 
be suggested that the high production of benzaldehyde in $R$. oligosporus USM R1 was a result of synergistic effect of in vivo biosynthesis and in vitro biotransformation of Lphenylalanine to benzaldehyde by extracellular enzymes. The possible enzyme systems may include the phenyl ammonia lyase for the conversion of L-phenyalanine to trans-cinnamic acid and benzaldehyde oxidase for the conversion of trans-cinnamic acid to benzaldehyde (Casey and Dobb, 1992) or aminotranferase enzyme which converted L-phenylalanine directly to benzaldehyde (Nierop Groot and de Bont, 1998).

The findings obtained in the present work strongly suggested that the SSF processes can be a highly economical approach for industrial production of fungal metabolites. Enhanced production of the flavouring compound, benzaldehyde can easily be achieved by manipulating the governing parameters of the SSF processes.

\section{ACKNOWLEDGEMENT}

The authors would like to thank the financial support from the National Biotechnology Directorate under the Top Down Food Biotechnology Research Grant. The work formed a part of the M.Sc thesis of Norliza A.W.

\section{REFERENCES}

Balakrishna, R. and Pandey A (1996). Production of biologically active secondary metabolites in soild state fermentation. Journal of Scientific and Industrial Research. 55: 365 - 372.

Bhattacharyya, B.C., Tunga, R. and Banerjee, R. (1998). Optimizing some factors affecting protease production under solid state fermentation. Bioprocess and Bioengineering. $19: 187-190$.

Casey, J. and Dobb, R. (1992). Microbial routes to aromatic aldehydes. Enzyme Microbial. Technology, $14: 739-747$.

Fassatiova, O. (1986). Moulds and filamentous fungi in technical Microbiology (Bushel M.E. Ed).Vol 22, pp 33 - 48. New York, Elsevier Publishing Co. Inc.

Feron, G., Bonnarme, P. and Durand, A. (1996). Prospects for the microbial production of food flavours. Trends Food Science and Technology, 7 : 285-293.

Hesseltine, C.W. (1972). Biotechnology report on solid state fermentations. Biotechnology and Bioengineering. 14 : 517-532.

Jensen, K.A., Evans, K.M.C., Kirk, T.K. and Hammel, K.E. (1994). Biosynthetic pathway for veratryl alcohol in the ligninolytic fungus Phanerochaete chrysosporium. Applied and Environmental Microbioogy. 60 : 709-714.

Kargi, F., Curme J.A. and Sheehan, J.J. (1985). Solid state fermentation of sweet sorghum to ethanol. Biotechnology and Bioengineering, 27 : 34-40.

Kawabe, T. and Morita, H. (1994). Production of benzaldehyde and benzyl alcohol by the mushroom
Polyporus tuberaster K2606. Journal of Agriculture and Food Chemistry, $42:$ 2556-2560.

Lapadatescu, C., Ferron, G., Vergoignan, C., Djian, A., Durand, A. and Bonnarme, P. (1997). Influence of cell immobilization on the production of benzaldehyde and benzyl alcohol by the white-rot fungi Bjerkandera adusta, Ischnoderma benzoinum and Dichomitus squalens. Applied. Microbiology and Biotechnology. $47:$ 708-714.

Laukevics, J.J., Aspite, A.F., Viesturs, U.E. and Tengerdy, R.P. (1984). Solid substrate fermentation of wheat straw to fungal protein. Biotechnology and. Bioengineering. 26 : 1465-1474.

Lawrence, G.D. and Yuan, D. (1996). Benzaldehyde formation from aspartame in the presence of ascorbic acid and transition metal catalyst. Journal of Agriculture and Food Chemistry. 44 : 3461-3466.

Leong S.Y. and Ibrahim, C.O. (2000). Optimization of a solid state fermentation for benzaldehyde production by a locally isolated, Penicillium diversum using palm kernel cake (PKC) as substrate. Pakistan Journal of Biological. Science. 3(10) : 1752-1754.

Moo-Young, M., Moriera, A.R. and Tengerdy, R.P. (1983). Principles of solid state fermentation. In The Filamentous Fungi, Vol. 4, Fungal Biotechnology (Smith, J.E., Berry, D.R. \& Kristiansen, E., ed.), p. 117-144. London: Edward Arnold Publishers.

Mudgett, R.E. (1980). Controlled gas environments in industrial fermentations. Enzyme and Microbial Technology. 3 : 273-280.

Ngadi, M.O. and Correia, L.R. (1992). Solid state ethanol fermentation of apple pomace as affected by moisture and bioreactor mixing speed. Journal of Food Science. 57: 667 - 670 .

Nierop Groot, M.N. and De Bont, J.A.M. (1998). Conversion of phenylalanine to benzadehyde initiated by an aminotransferase in Lactobacillus plantarum. Applied and Environmental Microbiology, 64(8) : 3009-3013.

Pitt, J.I and Hocking A.D (1999). Fungi and food spoilage (2nd Edition). A Chapman and Hall Food Science Book. Aspen Publisher. Gaiterburg, Maryland, USA, pp $173-201$.

Raimbault, M. (1998). General and microbiological aspects of solid state fermentation. Electronic Journal of Biotechnology, 1(3) : 234-252.

Righelato, R.C. (1975). Growth kinetics of mycelial fungi. In The Filamentous Fungi (Smith, J.E. and Berry, D.R., ed.), Vol. 1, 79-103. New York: John Wiley and Sons, Inc.

Roukas, T. (2000). Citric and gluconic acid production from fig by Aspergillus niger using solid state fermentation. Journal of Industrial Microbiology and. Biotechnology. 25 : 298-304.

Silman, R.W., Conway, H.F., Anderson, R.A. and Bagley, E.B. (1979). Production of aflatoxin in corn by a large scale solid substrate fermentation process. Biotechnology and. Bioengineering, 21: 1799-1808.

Swift, M.J. (1972). The estimation of mycelial biomass by determination of the hexosamine content of wood 
tissue decayed by fungi. Soil Biology and Biochemistry, 5: 321-332.

Tsou, A.Y., Ransom, S.C. and Gerlt, J.A. (1990). Mandelic acid pathway of Pseudomonas putida: sequence relationships involving mandelic acid racemase, (S)-mandelic acid dehydrogenase, and benzoylformate decarboxylase and expression of benzoylformate decarboxylase in Escherichia coli. Biochemistry, 29: 9856-9862.
Welsh, F.W., Murray, W.D., and Williams, R.E. (1989). Microbiological and enzymatic production of flavor and fragrance chemicals. Critical Reviews in Biotechnology, 9(2): 105-169.

Yadav, J.S. and Tripathi J.P. (1991). Optimization of cultivation and nutrition conditions and substrate pretreatment for solid substrate fermentation of wheat straw by Coriolus versicolor. Folia Microbiologica, 36: $294-301$. 